\title{
Natural convection in a Square Enclosure with Partially Active Vertical Wall
}

\author{
Abdennacer Belazizia ${ }^{1}$, Smail Benissaad ${ }^{2}$ and Said Abboudi $^{3}$ \\ ${ }^{1}$ Université Larbi Tebessi Tebessa Algérie \\ ${ }^{2}$ Laboratoire d'energétique appliquée et de la pollution. Université Mentouri Constantine1 Algérie \\ ${ }^{3}$ Laboratoire ICB Equipe COMM Université UTBM Belfort France
}

\begin{abstract}
Steady, laminar, natural convection flow in a square enclosure with partially active vertical wall is considered. The enclosure is filled with air and subjected to horizontal temperature gradient. Finite volume method is used to solve the dimensionless governing equations. The physical problem depends on three parameters: Rayleigh number $\left(R a=10^{3}-10^{6}\right)$, Prandtl number $(P r=0.71)$, and the aspect ratio of the enclosure $(A=1)$. The active location takes two positions in the left wall: top (T) and middle (M). The main focus of the study is on examining the effect of Rayleigh number on fluid flow and heat transfer rate. The results including the streamlines, isotherm patterns, flow velocity and the average Nusselt number for different values of Ra. The obtained results show that the increase of Ra leads to enhance heat transfer rate. The fluid particles move with greater velocity for higher thermal Rayleigh number. Also by moving the active location from the top to the middle on the left vertical wall, convection and heat transfer rate are more important in case (M). Furthermore for high Rayleigh number $\left(R a=10^{6}\right)$, Convection mechanism in (T) case is principally in the top of the enclosure, whereas in the remaining case it covers the entire enclosure.
\end{abstract}

\section{Introduction}

Various modes of convection are possible depending on how the temperature gradient and the gravity are oriented to each other. The stratified fluid can be subjected to horizontal or vertical temperature gradients [1]. This phenomenon is of considerable interest in a very wide range of fields. In nature such flow is encountered in the oceans, pollution dispersion in lakes, shallow coastal waters and the atmosphere [2].

In many studies natural convection is due to the imposed temperature gradients between the opposite walls of the enclosure taking the entire vertical wall to be thermally active [3-10]. But in many engineering applications such as solar energy collectors it is only a part of the wall which is thermally activated.

Many articles concerning natural convection in enclosures with partially active walls had been published. For example Nithyadevi et al. [11] studied numerically the effect of double diffusive natural convection of water in a partially heated enclosure with Soret and Dufour coefficients for either cooperating or opposing heat and mass gradients.

In this work we present a numerical study of laminar natural convection in a square enclosure filled with air and submitted to horizontal temperature gradient. The active location takes two positions in the left wall: top (T) and middle (M). The main focus is on examining the effect of Rayleigh number on fluid flow and heat transfer in the enclosure. The rate of heat transfer in the enclosure is measured in term of the average Nusselt number.

\section{Problem Geometry}

The geometry of the problem is shown in Fig.1. The partially heated active vertical left side wall $(h=H / 2)$ and fully heated active vertical right side wall of the enclosure are maintained at two different but uniform temperatures: $\left(T_{\max }>T_{\min }\right)$. The remaining boundaries of the enclosure are impermeable and thermally insulated.

\section{Basic Equations}

The flow in the enclosure is assumed to be twodimensional. All fluid properties are constant. The fluid is considered to be incompressible and Newtonien. The Boussinesq approximation is applied $\rho(T)=\rho_{0}\left[1-\beta_{t}\left(T-T_{0}\right)\right]$. Viscous dissipation, heat generation, and radiation effects are neglected. The governing non-dimensional mass, momentum and energy equations are as follows, respectively:

- at $t=0: U=V=0 ; \theta=0 ; 0 \leq X \leq 1,0 \leq Y \leq 1$

\footnotetext{
* Corresponding author: nacer.belazizia@gmail.com
} 


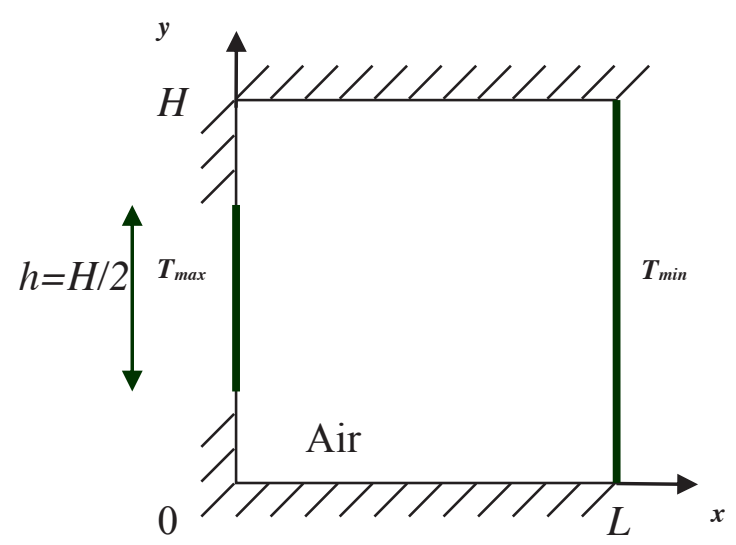

Fig 1. Physical configuration.

- for $t>0$;

$$
\begin{gathered}
\frac{\partial U}{\partial X}+\frac{\partial V}{\partial Y}=0 \\
\frac{\partial U}{\partial t}+U \frac{\partial U}{\partial X}+V \frac{\partial U}{\partial Y}=-\frac{\partial P}{\partial X}+P_{r} \nabla^{2} U \\
\frac{\partial V}{\partial t}+U \frac{\partial V}{\partial X}+V \frac{\partial V}{\partial Y}=-\frac{\partial P}{\partial Y}+P_{r} \nabla^{2} V+P_{r} \cdot R a \cdot \theta \\
\frac{\partial \theta}{\partial t}+U \frac{\partial \theta}{\partial X}+V \frac{\partial \theta}{\partial Y}=\nabla^{2} \theta
\end{gathered}
$$

The boundary conditions in the dimensionless form are:

$$
\begin{gathered}
X=0: U=V=0, \text { for } 0 \leq Y \leq 1 \\
X=0: \theta=1, \text { for } Y \geq 1 / 2 \text { or } 3 / 4 \geq Y \geq 1 / 4 \\
X=1: U=V=0, \theta=0,0 \leq Y \leq 1 \\
Y=0: U=V=0, \frac{\partial \theta}{\partial X}=0, \text { for } 0 \leq X \leq 1 \\
Y=1: \quad U=V=\frac{\partial \theta}{\partial Y}=0 \text { for } 0 \leq X \leq 1
\end{gathered}
$$

The average Nusselt number:

$$
\begin{array}{ll}
\text { Left wall: } & \overline{N u}=-\int_{h} \frac{\partial \theta}{\partial X} d y ; \\
\text { Right wall: } & \overline{N u}=-\int_{0}^{1} \frac{\partial \theta}{\partial X} d y
\end{array}
$$

\section{Numerical Methode}

The governing equations (1) to (4) associated with the boundary conditions (5) are solved numerically using the finite volume method described by Patankar [13]. A uniform mesh is used in $X$ and $Y$ directions. A hybrid scheme and first order implicit temporally discretisation are used. Because of the nonlinearity of the momentum equations, the velocity pressure coupling, and the coupling between the flow and the energy equation, an iterative solution is necessary. The SIMPLER algorithm and Tri-Diagonal Matrix algorithm iteration procedure [13] are used to solve the algebraic equations. The iteration process is terminated under the following conditions:

$$
\sum_{i, j}\left|\phi_{i, j}^{n}-\phi_{i, j}^{n-1}\right| / \sum_{i, j}\left|\phi_{i, j}^{n}\right| \leq 10^{-5}
$$

Where $\phi$ represent: $U, V$ and $\theta$; n denotes the iteration step.

$$
\left.\overline{N u}\right|_{X=0}=\left.\overline{N u}\right|_{X=1}
$$

In order to obtain a precise results a $(60 \times 60)$ grid was selected and used in all the computations Tab1. A good agreement between the obtained results and thaws reported in literature [12] are observed (Tab.2).

Table 1. Average Nusselt number for different grid sizes.

\begin{tabular}{|c|c|c|c|c|c|}
\hline Mesh & $30 \times 30$ & $40 \times 40$ & $50 \times 50$ & $60 \times 60$ & $70 \times 70$ \\
\hline$\overline{N u}$ & 3.57 & 3.52 & 3.49 & 3.48 & 3.48 \\
\hline
\end{tabular}

Table 2. Average Nusselt number for different Rayleigh number.

\begin{tabular}{|c|c|c|}
\hline $\boldsymbol{R} \boldsymbol{a}$ & present study & {$[\mathbf{1 2}]$} \\
\hline $10^{3}$ & 1.118 & 1.116 \\
\hline $10^{4}$ & 2.251 & 2.238 \\
\hline $10^{5}$ & 4.480 & 4.509 \\
\hline
\end{tabular}

\section{Results and Discussions}

\subsection{Effect of Rayleigh number}

Fig. 2 shows the effect of thermal Rayleigh number on fluid motion inside the enclosure for different locations in the left vertical wall: top (T) and middle (M). A single cell rotating in clockwise direction $(\psi<0)$ appears inside the enclosure. For the case (M) and for $R a \geq 10^{5}$ Fig.2 (b) streamlines cover the entire enclosure and the centre of each cell is elongated and two secondary cells appear inside it. Also for the two cases ( $\mathrm{T}$ and $\mathrm{M}$ ) we observe that the maximum absolute value of the stream function $|\psi|_{\max }$ increase with the increase of Rayleigh number. Which means natural convection is strength. In addition by moving of the active location from the top to the middle, $|\psi|_{\max }$ in the case (M) is the greatest. Therefore convection is more important for this location. It is observed also that the fluid particles move with greater 
velocity for higher thermal Rayleigh number, as mentioned in Fig. 3 showing the effect of $R a$ on midheight horizontal and vertical velocity profiles. The velocity peaks especially near the vertical walls are more important for both high $R a$ and middle (M) location.

(a)
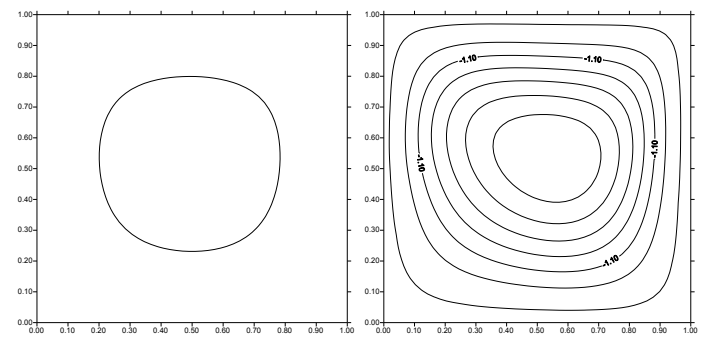

$\boldsymbol{R} \boldsymbol{a}=1 \mathbf{0}^{3},|\psi|_{\max }=0.91$

$\boldsymbol{R a}=\mathbf{1 0}^{4},|\psi|_{\max }=3.55$

(a)
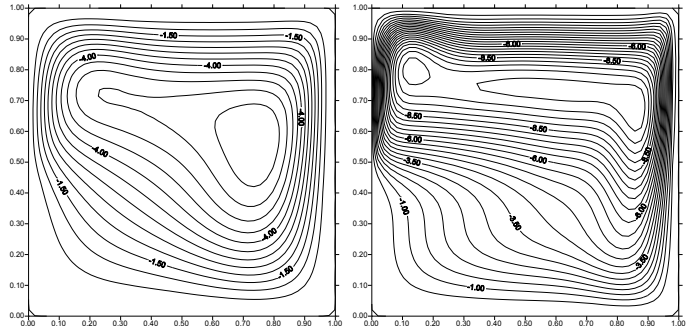

$\boldsymbol{R a}=10^{5},|\psi|_{\max }=6.47$

$\boldsymbol{R} \boldsymbol{a}=10^{6},|\psi|_{\max }=10.97$

(b)
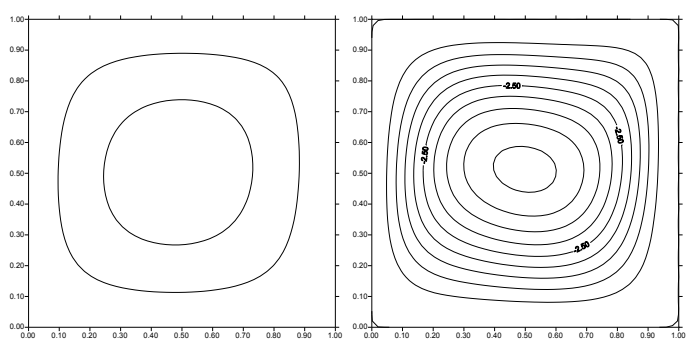

$\boldsymbol{R} \boldsymbol{a}=\mathbf{1 0}^{3},|\psi|_{\max }=1.10 \quad \boldsymbol{R} \boldsymbol{a}=\mathbf{1 0}^{4},|\psi|_{\max }=4.66$

(b)
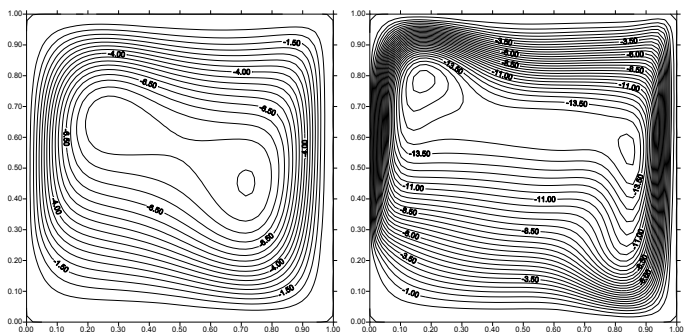

$\boldsymbol{R} \boldsymbol{a}=10^{5},|\psi|_{\max }=8.55 \quad \boldsymbol{R} \boldsymbol{a}=10^{6},|\psi|_{\max }=15.74$

Fig 2. Steady state of streamlines: Top (a), Middle (b) for different values of Rayleigh number.
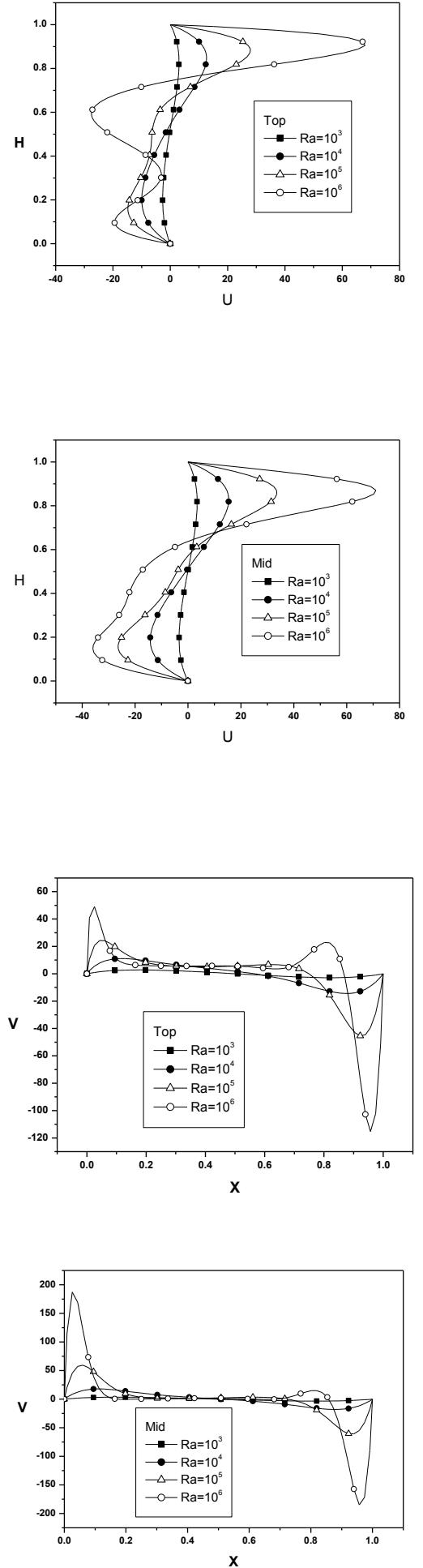

Fig 3. Axial velocity $U$ at $X=0.5$ and vertical velocity $V$ at $Y=0.5$.

The effect of thermal Rayleigh number on thermal field is illustrated in Figs.4. The isotherms are crowded around the active location on the left side of the enclosure. The fluid rises along the hot wall and falls along the right cold wall, so thermal gradient are very important in these regions. Convection mechanism in (Top) case is principally in the top of the enclosure for 
high Rayleigh number $\left(R a=10^{6}\right)$, whereas in the auther case it covers the entire enclosure. For low $R a_{t}$ the isotherms shown in Fig.4 (a,b) are almost parallel to the vertical walls, indicating that most of the heat transfer is by heat conduction. For high Rayleigh number $\left(R a=10^{5}\right.$ and $10^{6}$ ) there is a temperature stratification in the vertical direction indicating the dominant of convection heat transfer mechanism.

The rate of heat transfer across the cavity is obtained by evaluating the average Nusselt number at the cavity walls. Fig. 5 presents the effect of thermal Rayleigh number on $\overline{N u}$ for the two locations in the left vertical wall: It is clear from this figure that for a given active location the average Nusselt number is increasing with Rayleigh number. Comparing the two cases ( $\mathrm{T}$ and $\mathrm{M}$ ) $\overline{\mathrm{Nu}}$ are nearly the same for low Rayleigh number $\left(R a=10^{3}\right)$. This indicates that most of heat transfer is dominated by diffusion mode. While for $R a>10^{3} \overline{N u}$ is less important in (Top) case. In consequence we can note that the position of the active location has a noticeable effect on the rate of heat transfer and fluid velocity.

(a)
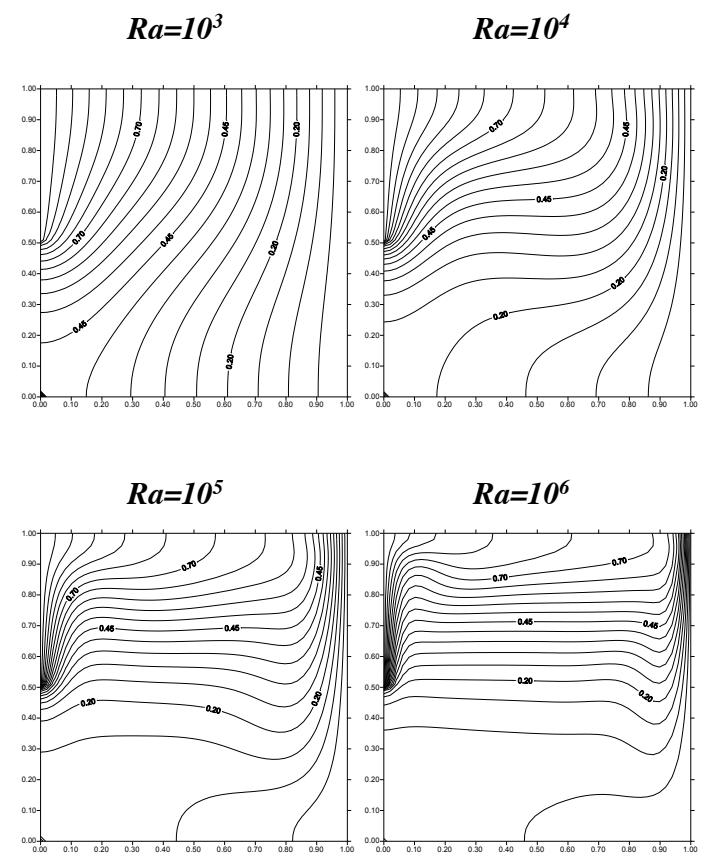

(b)

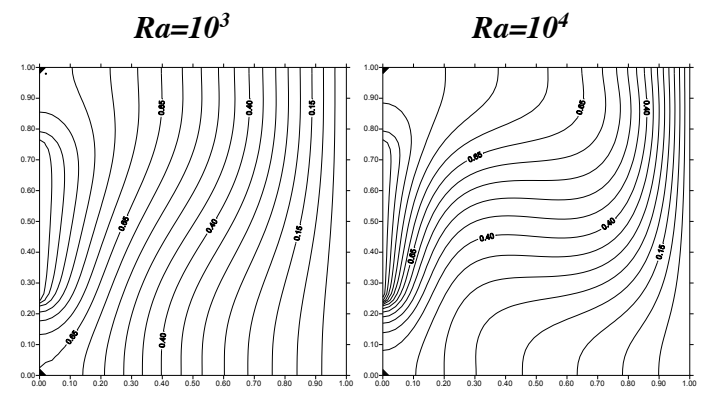

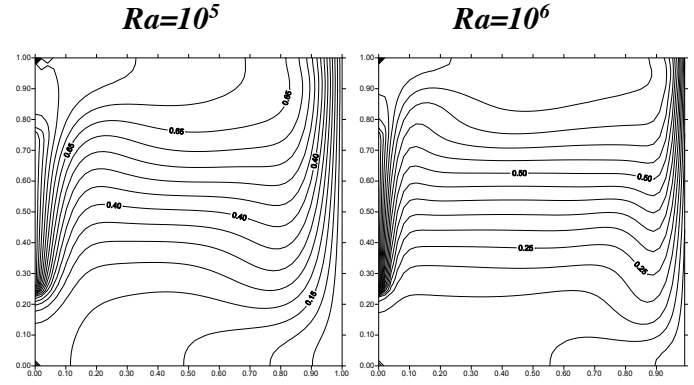

Fig 4. Steady state of isotherms: Top (a), Middle (b) for different values of thermal Rayleigh number.

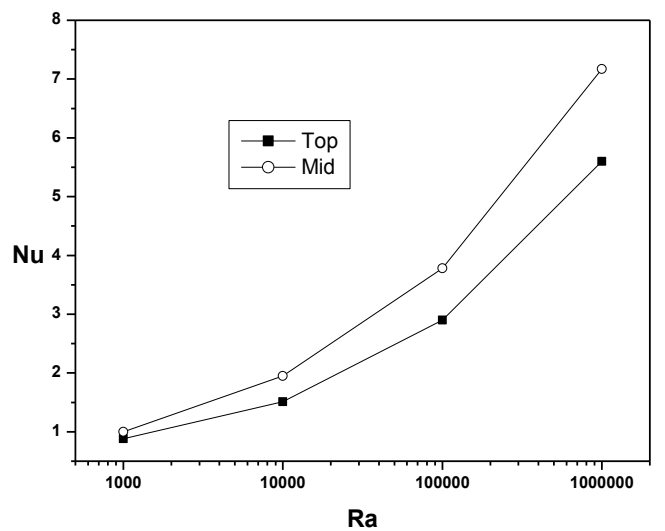

Fig 5. Average Nusselt number for different values of Rayleigh number.

\section{Conclusion}

A numerical study of natural convection was employed to analyze the flow and heat transfer of air filled in a square enclosure with top (T) and middle (M) active location of the left vertical wall. The following conclusions are summarized. The position of the active location has a noticeable effect on flow field and heat transfer in the enclosure. It is found that the rate of heat transfer increases with thermal Rayleigh number. Convection in case $(\mathrm{T})$ is less important comparing with the case (M).

\section{References}

1. Y. Kamotani, J. S. Wang, S. Ostrah, H. D. Jiang, Int. J. Heat Mass ransfer, 28(1), (1985).

2. M. Ouriemi, P. Vasseur, A. Bahloul, L. Robillard, Int. J. Thermal Sciences, 45, (2006).

3. A. Valencia, R. L. Frederick, Int. J. Heat Mass Transfer, 32, (1989).

4. N. Yucel, H.Turkoglu, 29. (1994).

5. R. L. Frederick, and F. Quiroz, Inj. J. Heat Mass Trans, 44, (2001). 
6. B. Erbay, Z. Altac, B. Sulus, Heat Mass Transfer, 40, (2004).

7. N. Nithyadevi, P. Kandaswamy, J. Lee, Int. J. Heat Mass Transfer, 50, (2007).

8. H.F. Oztop. Int. J. Therm. Sci, 46, (2007).

9. P. Kandaswamy, S. Sivasankaran, N. Nithyadevi, Int. J. Heat Mass Transfer, 50, (2007).

10. N. Nithyadevi, and R.J. Yang, Int. J. Heat and Fluid Flow, 30, (2009).

11. N. Nithyadevi, and. R.J Yang, Int. J. Heat and Fluid Flow, 30, (2009).

12. G. D. Vahl Davis, Int. J. Num. Mesh. Fluids, 3, (1983).

13. S. V. Patankar, McGraw-ill, Washington, DC, (1980).

\section{Nomenclature}

A aspect ratio, $H / L$

$\overline{\mathrm{Nu}} \quad$ average Nusselt number

$P \quad$ dimensionless pressure, $p /(\alpha / H)^{2}$

$\operatorname{Pr} \quad$ Prandtl number of the fluid, $v / \alpha$

$R a_{t} \quad$ thermal Rayleigh number, $g \beta_{t} H^{3} \Delta T / v \alpha$

$t \quad$ dimensionless time, $t^{*} /\left(H^{2} / \alpha\right)$

$U, V \quad$ dimensionless velocity components, $u /(\alpha / H)$, $v /(\alpha / H)$

$X, Y \quad$ non-dimensional cartesian coordinates, $x / H$, $y / H$

\section{Greek symbols}

$\theta \quad$ non-dimensional temperature, $\left(T-T_{\min }\right) / \Delta T$

$\psi \quad$ non-dimensional stream function, $U=\partial \psi / \partial Y$

$\Delta T \quad$ temperature difference, $\left(T_{\max }-T_{\min }\right)$ 